${ }^{1}$ Facultad de Medicina Universidad del Desarrollo Clínica Alemana de Santiago. Santiago, Chile.

Departamento de Radiólogía, Clínica Alemana de Santiago. Santiago, Chile.

'Departamento de Anatomía Patológica, Clínica Alemana de Santiago. Santiago, Chile. ${ }^{a}$ Residente de Radiología.

Trabajo no recibió financiamiento. Los autores declaran no tener conflictos de interés.

Recibido el 9 de abril de 2019, aceptado el 3 de octubre de 2019.

Correspondencia a: Dr. Javier Cacho Olivares Esperanza 2150, San Ramón. Santiago, Chile. jcachoo@gmail.com

\section{Enfermedad quística adventicial de la arteria poplítea. Presentación imagenológica de una causa rara de claudicación intermitente}

\author{
JAVIER CACHO ${ }^{1, \mathrm{a}}$, JUAN PABLO OLIVARES ${ }^{1, \mathrm{a}}$, JORGE DÍAZ JARA², \\ MARÍA IGNACIA FAURE ${ }^{1, a}$, YUMAY PIRES ${ }^{3}$
}

\section{Adventitial cystic disease of the popliteal artery as a cause of intermittent claudication: not your usual suspect. Report of one case}

\begin{abstract}
Adventitial cystic disease of the popliteal artery is a rare condition of uncertain etiology, which presents as intermittent claudication of the lower extremity in middle-age patients. We report a 44-year-old man presenting with intermittent claudication of his left leg. MR angiography showed cystic parietal lesions that caused compression with partial occlusion of the left popliteal artery. Surgical resection of the affected segment was performed, with venous graft interposition. The histopathological analysis of the surgical specimen was consistent with cystic adventitial disease.
\end{abstract}

(Rev Med Chile 2019; 147: 1206-1209)

Key words: Cysts; Magnetic Resonance Angiography; Popliteal Artery.

\section{L} a enfermedad quística adventicial de la arteria poplítea es una causa rara de claudicación intermitente de las extremidades inferiores, con, aproximadamente, solo 500 casos publicados en la literatura ${ }^{1}$. Generalmente, afecta a hombres de mediana edad ${ }^{2}$, en donde la patología vascular es rara, por lo que es frecuentemente confundida clínicamente con otras entidades más prevalentes en este grupo etario. A continuación, presentamos un caso clínico de un paciente de 44 años que consultó con un cuadro de claudicación intermitente en la región gemelar izquierda, inicialmente interpretado como un desgarro muscular.

\section{Caso clínico}

Paciente sexo masculino de 44 años, sin antecedentes mórbidos, consultó por cuadro de dolor gemelar izquierdo con el ejercicio, de 1 mes de evolución, sin historia de trauma. Inicialmente, se sospechó el diagnóstico de un desgarro muscular, por lo que se realizó una ecografía de partes blandas, la cual resultó normal.

$\mathrm{Al}$ interrogatorio dirigido, el paciente refería cuadro compatible con claudicación intermitente de la región gemelar izquierda gatillado al caminar aproximadamente 200 metros.

$\mathrm{Al}$ examen físico destacaba disminución del pulso poplíteo izquierdo, con ausencia de los pulsos distales. No se identificaba frialdad ni palidez de la extremidad inferior izquierda.

En este contexto se solicitó una ecografía Doppler arterial de la extremidad inferior izquierda en donde destacaba suboclusión de la arteria poplítea, por material endoluminal sugerente de trombosis segmentaria, con repermeabilización a distal, posiblemente por flujo de colaterales (Figura 1a).

Se inició anticoagulación oral y se indicó una resonancia magnética ( $\mathrm{RM})$ de rodilla y angioRM de la extremidad inferior izquierda para mejor caracterización de los hallazgos y descartar un síndrome de atrapamiento poplíteo. La angioRM 
mostró engrosamiento parietal segmentario de la arteria poplítea izquierda, con imagen quística parietal, que determinaba leve estenosis a este nivel, compatible con enfermedad quística adventicial de la arteria poplítea (Figura 1b y 1c).

Con estos antecedentes se programó cirugía de reparación, en la cual se describió un segmento dilatado de la arteria poplítea de $10 \mathrm{~cm}$ con vasos de neoformación en la periferia. Dicho segmento fue resecado y reemplazado con autoinjerto obtenido desde la vena safena interna de la misma extremidad. El paciente evolucionó satisfactoriamente, con recuperación de los pulsos distales izquierdos, por lo que fue dado de alta.

El estudio histológico del segmento arterial demostró un segmento de la arteria con degeneración mixoide transmural, con acumulación de mucopolisacáridos y formación de múltiples cavidades, comprometiendo las túnicas media y adventicia (Figura 2).

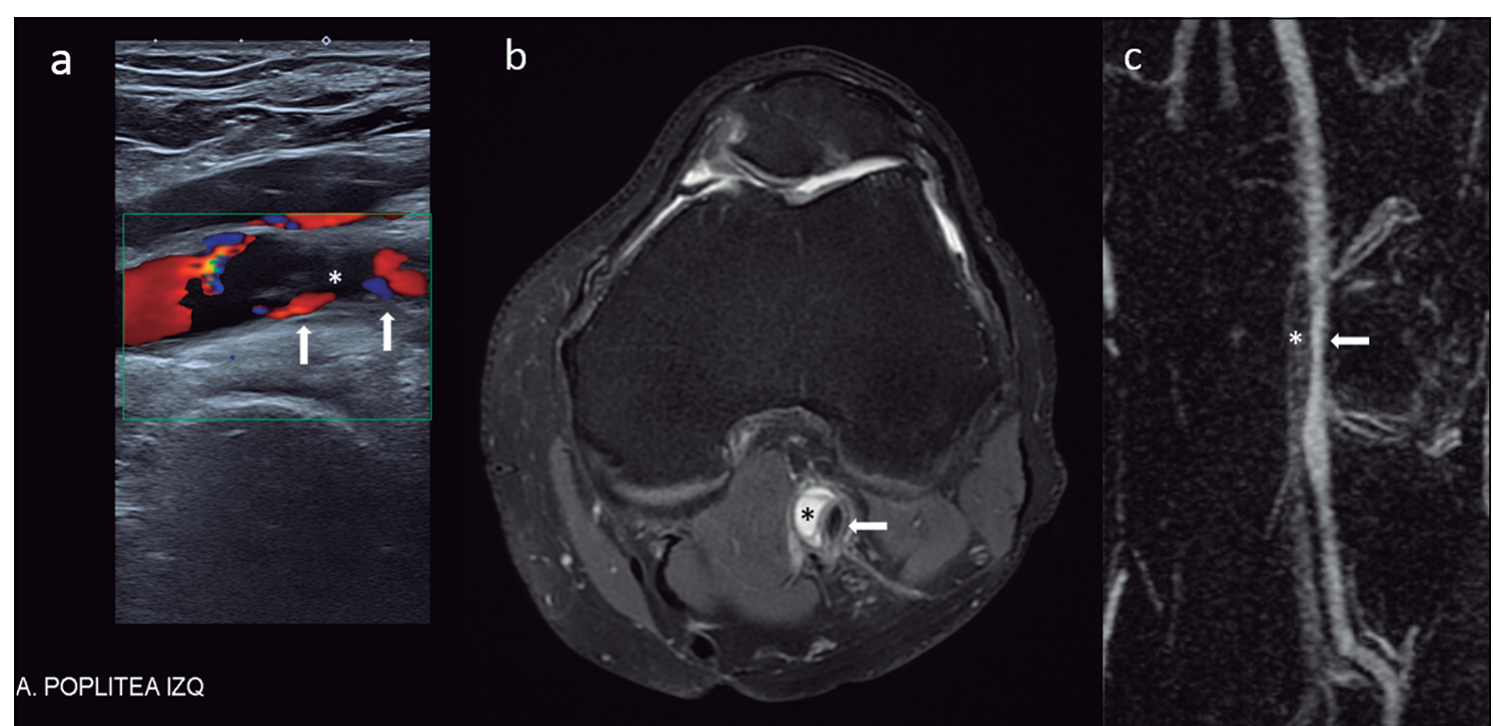

Figura 1. a) Ultrasonido Doppler color que muestra suboclusión de la arteria poplítea izquierda, la cual se encuentra ocupada por material hipoecogénico (asterisco). Presenta flujo filiforme periférico (flechas). b) Adquisición axial de RM potenciada en densidad protónica con saturación grasa, que muestra engrosamiento parietal de la arteria poplítea izquierda, con imagen quística en su aspecto anteromedial y algunos tabiques en su espesor (asterisco). El lumen estenótico presenta normal "vacío de señal" (flecha). c) Reconstrucción coronal MIP de angiografía por RM, que muestra de mejor manera la extensión y el grado de estenosis (flecha), que alcanza aproximadamente 50\%, determinada por la lesión (asterisco).

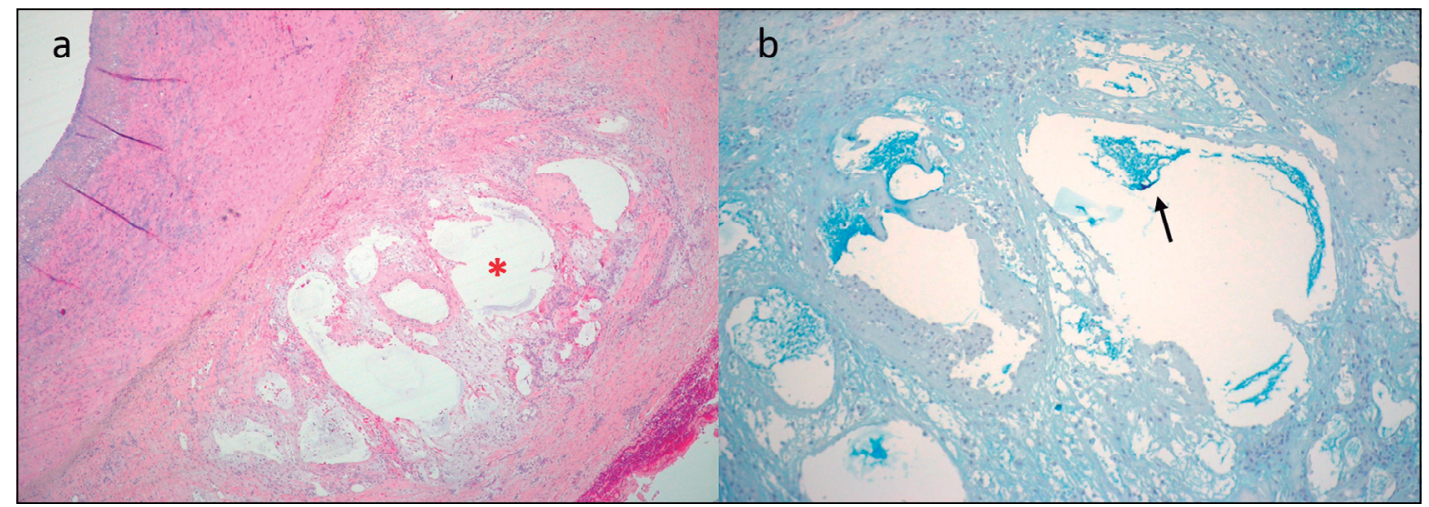

Figura 2. a) Pared arterial con degeneración mixoide que compromete predominantemente las túnicas media y adventicia, con formación de cavidades (asterisco) (tinción H-E x 10). b) Material rico en mucopolisacáridos en las cavidades presentes en la pared arterial (flecha) (tinción azul Alcian x 20). 


\section{Discusión}

La enfermedad quística adventicial de la arteria poplítea es una causa rara de claudicación intermitente de las extremidades inferiores, con aproximadamente 500 casos publicados en la literatura ${ }^{1}$. Generalmente afecta a hombres de mediana edad ${ }^{2}$, en quienes la patología vascular es rara, por lo que el diagnóstico no es sospechado inicialmente y se confunde con patologías más frecuentes en este grupo etario, como sucedió en nuestro caso. Además, los síntomas tienden a variar con el tiempo, con periodos en donde los pacientes son completamente asintomáticos, solo para recurrir meses o semanas después, lo que dificulta aun más su diagnóstico clínico ${ }^{4}$.

Esta entidad fue descrita por primera vez en 1947 en la arteria iliaca externa por Atkins y Key ${ }^{3}$. Desde entonces se han reportado múltiples casos, tanto en arterias como venas, siendo más prevalente en la arteria poplítea, representando $85 \%$ de los casos $^{5}$. Histopatológicamente, los vasos afectados presentan acumulación de proteoglicanos con formación de múltiples cavidades o espacios quísticos en la adventicia que contienen un gel mucinoso espeso ${ }^{6}$.

La etiología de esta enfermedad es desconocida y se han propuesto varias hipótesis para explicarla, incluyendo trauma repetitivo a la adventicia por flexión, llevando a degeneración quística de esta; origen embriológico; y ser consecuencia de herniación de estructuras sinoviales a través de una comunicación directa con la articulación adyacente $^{7}$. En el caso de nuestro paciente, la estructura quística en la adventicia de la arteria poplítea se encontraba completamente separada de la articulación, sin identificarse una comunicación entre ambas.

En el estudio por imágenes, el ultrasonido puede demostrar lesiones anecoicas o hipoecoicas en la pared arterial, con grado variable de estenosis del lumen y alteraciones de flujo al estudio Doppler (Figura 1a).

El estudio angiográfico, ya sea por tomografía computada (TC) o resonancia magnética (RM), va a demostrar la estenosis del vaso comprometido que podría presentar morfología de "reloj de arena" ". Las lesiones parietales serán hipodensas en la TC, mientras que en RM tendrán alta señal en secuencias potenciadas en T2, y señal variable en T1 dependiendo del contenido (Figura 1b y 1c). La angiografía convencional es una técnica invasiva reservada para casos seleccionados donde podría aportar mayor información que la TC o RM.

El principal diagnóstico diferencial que debemos considerar en el contexto de nuestro paciente (joven y sin antecedentes mórbidos) es el de un síndrome de atrapamiento poplíteo, en donde la estenosis de la arteria poplítea es secundaria a compresión u oclusión debido a un curso anómalo de esta, o variantes en las inserciones de los grupos musculares regionales. Esto fue descartado con la $\mathrm{RM}$ de rodilla, que no mostraba variaciones en la anatomía regional. Otros diagnósticos diferenciales que considerar son la estenosis de origen ateromatoso y la oclusión arterial de origen embólico, entidades raras en pacientes presuntamente sanos y de este grupo etario.

El tratamiento de esta patología ha sido basado en la experiencia de los reportes de casos documentados. Se han propuesto varias modalidades de tratamiento, que varían desde la aspiración del quiste guiada por ultrasonido a la resección abierta, angioplastia por balón y bypass con o sin resección del quiste ${ }^{9,10,11}$. En una de las series de casos más actuales, el procedimiento quirúrgico de elección fue la resección del segmento arterial afectado, asociado a un procedimiento de bypass o bien reconstrucción con injerto venoso, ya que se asocia a menor tasa de recurrencias ${ }^{1,11}$.

Pese a que la enfermedad quística adventicial de la arteria poplítea es una entidad rara, esta debe ser sospechada en pacientes jóvenes, sin factores de riesgo para ateroesclerosis, que se presentan con claudicación intermitente de las extremidades inferiores. Esto evita retrasos en el diagnóstico y tratamiento de esta enfermedad.

\section{Referencias}

1. Motaganahalli R, Harlander-Locke M, Lawrence $\mathrm{P}$, Fujimura N, DeMartino R, et al. A multiinstitutional experience in adventitial cystic disease. J Vasc Surg 2017; 65: 156-61.

2. Tomasian A, Lai C, Finn J, Gelabert H, Krishnam M. Cystic adventitial disease of the popliteal artery: features on 3T cardiovascular magnetic resonance. J Cardiovasc Magn Reson 2008; 10: 38.

3. Atkins H, Key J. A case of myxomatous tumour arising in the adventitia of the left external iliac artery. BJS 1947; 34: 426-7.

4. Vos L, Tielbeek A, Vroegindeweij D, van den Bosch H, 
Buth J. Cystic adventitial disease of the popliteal artery demonstrated with intravascular ultrasound. J Vasc Interv Radiol 1996; 7: 583-6.

5. Ishikawa K. Cystic adventitial disease of the popliteal artery and of other stem vessels in the extremities. Jpn J Surg 1987; 17: 221-9.

6. Peterson J, Kransdorf M, Bancroft L. Murphey M. Imaging Characteristics of Cystic Adventitial Disease of the Peripheral Arteries: Presentation as Soft-Tissue Masses. AJR 2003; 180: 621-5.

7. Nishibe M, Nishibe T, Yamashita T, Kato H, Kudo F, Yasuda K. Cystic adventitial disease of the popliteal artery. Etiologic considerations. J Cardiovasc Surg 2002;
43: 573-4.

8. Wright LB, Matchett WJ, Cruz CP, James C, Culp W, Eidt J, McCowan T. Popliteal artery disease: diagnosis and treatment. Radiographics 2004; 24: 467-79.

9. Ortiz M, Lopera J, Giménez C, Restrepo S, Moncada R, Castañeda-Zúñiga W. Bilateral Adventitial Cystic Disease of the Popliteal Artery: A Case Report. Cardiovasc Intervent Radiol 2006; 29: 306-10.

10. Levien L, Benn C. Adventitial cystic disease. A unifying Hypothesis. J Vasc Surg 1998; 28: 193-205.

11. Warhadpande S, Go M, El Sayed H, Satiani B, Vaccaro P. Popliteal artery cystic adventitial disease: Early lessons in treatment. Ann Vasc Surg 2017: 38; 255-9. 